\title{
Relationship between Mindfulness, Social Support, and Turnover Intention of Early Childhood Teachers
}

\author{
Mi Ae Kim, Sung-je $\mathrm{Cho}^{2)}$ \\ 유아 교사의 마음 챙김, 사회적 지지, 이직 의도와의 관계 \\ 김미애1), 조성제2)
}

\begin{abstract}
The purpose of this study is to grasp the relationship between early childhood teacher's mindfulness, social support, and turnover intention. The study was conducted on 115 infant teachers at $\mathrm{OO}$ city. As an analysis method, reliability analysis, frequency analysis, and correlation analysis were performed using the SPSS 22.0 program, and multiple regression analysis was performed on the causal relationship between variables. As a result of the study, first, it was found that the de-centered attention and present awareness factors, which are sub-factors of the mindfulness of early childhood teachers, had a significantly negative (-) effect on turnover intention. Second, early childhood teachers' mindfulness and social support had a significantly negative (-) effect on their turnover intentions. Third, the information support and material support factors, which are the sub-factors of social support for early childhood teachers, were found to have a significant negative (-) effect on turnover intention, and the emotional support and evaluation support factors had no significant effect. This means that the higher the degree of decentralization of mindfulness and present awareness perceived by early childhood teachers and the more informational support and material support of social support, the lower the turnover intention. The implications of this study are considered to be the basic data for the development of capacity building programs for the preparation of measures to reduce the intention of turning off early childhood teachers.
\end{abstract}

Keywords: Early Childhood Teacher, Mindfulness, Social Support, Turnover Intention, Emotional Support

$$
\text { 요 약 }
$$

본 연구의 목적은 유아 교사의 마음 챙김, 사회적 지지, 이직 의도와의 관계를 파악하는 데 있다. 연 구대상은 OO시 유아 교사 115명을 대상으로 실시하였다. 분석방법은 SPSS 22.0 프로그램을 사용하여,

Received(June 13, 2020), Review Result(1st: August 4, 2020, 2nd: September 23, 2020), Accepted(October 28, 2020)

1) (Ph. D. course) 02838 Dept. of Culture and Art, Dongbang Culture Graduate University, 28 Sungbok-Ro, Sungbokdong, Seoul, Korea

email: ehdg3624@hanmail.net

2) (Professor, Corresponding Author) 02838 Dept. of Culture and Art, Dongbang Culture Graduate University, 28 Sungbok-Ro, Sungbokdong, Seoul, Korea

email: chosj715@daum.net 
타당도 및 신뢰도 분석, 상관분석, 다중회귀분석을 수행하였다. 연구결과 첫째, 유아 교사의 마음 챙김 하위요인인 탈 중심적 주의, 현재 자각 요인은 이직 의도에 부적(-)으로 유의한 영향을 미치는 것으로 나타났다. 둘째, 유아 교사의 마음 챙김과 사회적 지지는 이직 의도에 부적(-)으로 유의한 영향을 미 치는 것으로 나타났다. 셋째, 유아 교사의 사회적 지지 하위요인인 정보적 지지, 물질적 지지 요인은 이직 의도에 부적(-)으로 유의한 영향을 미치는 것으로 나타났으며, 정서적 지지, 평가적 지지 요인은 영향을 없는 것으로 확인되었다. 이는 유아 교사가 지각하는 마음 챙김의 탈 중심적 주의, 현재 자각 과 사회적 지지의 정보적 지지, 물질적 지지가 높을수록 이직 의도가 낮아진다는 것을 의미하는 것이 다. 본 연구의 시사점은 유아 교사의 이직 의도 감소 방안 마련을 위한 역량 강화 프로그램 개발의 기초자료가 될 것으로 사료된다.

핵심어: 유아 교사, 마음 챙김, 사회적 지지, 이직 의도, 정서적지지

\section{1. 서론}

\section{1. 연구의 필요성}

현대 사회에 접어들면서 전통적인 가족구조가 핵가족으로 변화되고 있으며, 가족의 기능도 달라지 고 있다. 가족의 전통적인 기능은 점차로 약화 혹은 소멸되고, 가정 내에서 여성의 사회 진출로 맞 벌이 부부가 증가되고 있다. 이러한 가족구조 변화로 자녀의 양육문제가 사회적인 문제화가 되고 있다. 이에 국가에서는 자녀 보육문제 해결의 일환으로, 영유아 보육법을 1991년 1월 14일 법률 제 4328호에 의해 최초로 제정하였다. 영유아보육법 제1조에 의하면, 영유아의 심신을 보호하고 건전 하게 교육하여 건강한 사회구성원으로 육성함과 아울러 보호자의 경제적, 사회적 활동이 원활하게 이루어지도록 함으로써 영유아 및 가정의 복지 증진에 이바지함을 목적으로 제정된 법이다. 이를 근거로 국가에서는 유아교육기관에 대해 재정을 지원함과 동시에 양질의 영유아 교육서비스를 제 공해 줄 것을 요구하고 있다. 유아교육기관은 유아 교사가 유아를 대상으로 교육과 보육을 담당하 는 교육기관이며, 유아에게 양질의 교육과 보육을 제공하기 위해 우수한 유아 교사를 확보하는 것 은 매우 중요하다. 이러한 교육서비스의 질은 유아교육 프로그램, 시설, 원장, 유아 교사 등 다양한 요인이라고 볼 수 있다. 이러한 요인 중에서 유아 교사가 양질의 보육서비스를 제공하는데 가장 핵심적인 전문인력[1]이라고 보고되고 있다.

유아 교사의 교육의 질은 영유아에게 보육뿐만 아니라 유아의 전인 발달에 있어서 매우 중요한 요인이다[2]. 따라서 영유아의 건강한 교육을 위해서는 유아 교사의 전문적인 지식과 경험을 갖춘 훌륭한 교사 확보가 중요하다[3]. 반면, 유아 교사는 “타 교직의 임금과 달리 저임금이며, 사회적 인식도 낮고, 유아의 질적 보육과 교육에 대한 높은 사회적 요구와 기대로 이직 의도가 높다는 것 이 확인되었다"[4]. 또한 “교사에 대한 과도한 업무와 장시간의 보육, 낮은 사회적 인식, 낮은 보 수, 고용의 불안정 등은 교사가 보육에 전념하지 못하고 이직을 생각하게 하는 원인이며, 보육에 소홀함이 생길 수 있다"[5]. 이렇듯 교사의 이직은 양질의 보육 및 교육 서비스에 부정적인 영향을 미치므로, 유아 교사의 이직에 관련된 원인을 파악하고, 이직에 대한 해결방안에 대해 연구할 필요 
가 있다고 본다.

유아 교사의 이직 의도를 살펴보면, 임난주과 김안나(2014)은 유아 교사의 이직 의도에 대한 미 치는 영향력을 분석한 결과, 직무스트레스의 업무 과부하가 이직 의도에 유의미한 영향을 미쳤으 며, 직무만족도에서는 근무환경과 직무 자체의 특성이 이직 의도에 유의한 영향을 미치는 것으로 파악되었다[6]. 또한 유아 교사의 직무만족도는 이적의도를 낮추는 긍정적인 요인임을 알 수 있다. 최현성(2017)의 연구결과 보면, 유아 교사의 직무만족도는 소진과 이직 의도에 부정적인 영향을 미 쳤으며, 소진은 이직 의도에 긍정적인 영향을 미치는 것으로 나타났다[7]. 결과적으로 유아 교사의 소진과 이직 의도를 감소시키기 위해 직무만족도는 중요한 요소이며, 직무만족도를 증진하기 위해 서는 심리적 요소인 마음 챙김이 중요하다. 그 이유는 유아 교사의 감정노동과 소진과의 관계에 서 마음 챙김이 수용을 거쳐 소진을 완화할 수 있다고 확인되었다[8].

한편, 사회적 지지가 유아 교사의 이직 의도에 대해 간접효과를 미치는 것으로 나타났으며, 유 아 교사의 심리적 요인인 우울은 소진을 거쳐 이직 의도에 큰 영향을 미치는 변인임을 확인할 수 있었다[9]. 이 의미는 사회적 지지가 높을수록 이직 의도가 낮아진다는 것으로 볼 수 있다. 또한 영아보육교사를 대상으로 한 연구에서도 사회적 지지가 높을수록 낮은 심리적 소진으로 나타났다

고 하였다[10]. 이러한 연구결과를 요약하면, 유아 교사의 이직 의도에 영향을 미치는 또 다른 변 인으로는 사회적 지지라고 가정할 수 있다. 따라서 유아 교사의 이직 의도에 영향을 미치는 사회 적 지지의 원인변수를 분석하고, 이직에 대한 해결방안에 대해 연구할 필요성이 요구된다.

기존 선행연구를 종합적으로 분석하면, 유아 교사의 심리적 변인인 소진과 우울 등으로 이직 의 도를 낮추는 연구가 필요하다. 그 이유는 유아 교사의 이직은 양질의 보육 및 교육 서비스에 부정 적인 영향을 미쳤으며, 유아의 전인 발달에 있어서 매우 중요한 요인으로 보고되었다. 이에 유아 교사의 이직에 관련된 원인을 파악하고, 이직에 대한 해결방안에 대해 연구할 필요가 있다고 본다. 따라서 본 연구에서는 유아 교사들의 마음 챙김, 사회적 지지, 이직 의도와의 영향관계를 파악함으 로써 유아 교사들이 지각하는 이직 의도 감소 방안 모색을 제안하고자 한다.

\section{2 연구문제}

본 연구의 목적은 유아 교사의 마음 챙김, 사회적 지지, 이직 의도와의 관계에 대하여 분석하고자 한다. 이에 대한 세부적인 연구에 대한 내용은 아래와 같다.

1) 유아 교사의 마음 챙김, 사회적 지지, 이직 의도 간의 상관은 어떠한가?

2) 유아 교사의 마음 챙김은 이직 의도에 어떠한 영향을 미치는가?

3) 유아 교사의 사회적 지지는 이직 의도에 어떠한 영향을 미치는가? 


\section{2. 연구방법}

\section{1 연구대상}

본 연구는 2019년 9월 1일부터 2019년 11월 30일까지 00시의 유아 교사 115명을 대상으로 조사하 였다. 설문조사는 설문 대상자에게 설문 내용을 상세히 설명한 후 설문을 자기기입식으로 실시하 였다. 연구자료는 총 125 부의 자료를 수집한 후 불성실한 설문지 10 부를 제외한 115 부의 자룔를 분석에 활용하였다.

\section{2 연구도구}

본 연구에 사용된 측정도구는 일반적 특성 3 문항, 마음 챙김 20 문항, 사회적 지지 25 문항, 이직 의 도 4 문항으로 구성되어 있다. 일반적 특성에 관한 내용은 성별, 연령, 거주지 등으로 구성하여 조 사하였다. 유아 교사의 마음 챙김을 측정하기 위해 이우경[11]이 사용한 마음 챙김의 측정도구는 하위요인 탈중심적 주의 5 문항, 비판단적 수용 5 문항, 현재자각 5 문항, 주의집중 5 문항으로 전체 20 문항으로 설계하였다. 각 설문지 문항을 리커트 5점 척도로 구성하였다. 사회적 지지를 측정하기 위해 김기순[12]이 사용한 측정도구를 이용하였으며, 설문지 문항은 정보적 지지 6문항, 정서적 지 지 7문항, 물질적 지지 6문항, 평가적 지지 6문항으로 구성하였다. 각 설문지 문항은 리커트 5점 척도로 구성하였다. 유아 교사의 이직 의도를 측정하기 위해 박현주[13]가 사용한 이직 의도 측정 도구 4 문항으로 설계하였다. 그리고 각 설문지 문항은 리커트 5점 척도로 구성하였다.

\section{3 신뢰도}

본 연구에 사용된 각 변수의 신뢰도 검증결과, 마음 챙김의 전체 신뢰도는 .878 의 높은 신뢰도를 보이고 있다. 하위요인별로 살펴보면, 탈중심적 주의 .810 , 비판단적 수용 .832 , 현재자각 .854 주의 집중 .870 의 높은 신뢰도를 보이고 있다. 사회적 지지의 전체 신뢰도는 .907로 상당히 높게 나타났 으며, 하위요인별로 살펴보면 정서적 지지 .846, 정보적 지지 .884, 물질적 지지 .913, 평가적 지지 .880로 높게 나타났음을 알 수 있다. 이직 의도 또한 .909의 높은 신뢰도를 보이고 있다. 신뢰도 분 석결과에 대한 내용은 [표 1]과 같다.

\section{4 통계처리 및 분석방법}

연구에 수집된 자료처리는 SPSS 22.0 프로그램을 이용하여 분석하였고, 통계처리에서 유의수준 $5 \%$ 에서 검증을 실시하였다. 각 연구도구의 신뢰도 검증은 Cronbach's a의 계수를 적용하였다. 유아 
교사의 일반적 특성은 빈도분석을 실시하여 알아보았으며, 유아 교사의 마음 챙김이 이직 의도에 미치는 영향을 알아보기 위하여 상관분석 및 다중회귀분석을 수행하였다.

[표 1] 측정 변수의 신뢰도

[Table 1] Reliability of Measurement Variables

\begin{tabular}{lcccc}
\hline & 구분 & 문항수 & \multicolumn{2}{c}{ Cronbach's $\alpha$} \\
\hline \multirow{4}{*}{ 마음 챙김 } & 탈중심적 주의 & 5 & .810 & \\
& 비판단적 수용 & 5 & .832 & .878 \\
& 현재자각 & 5 & .854 & \\
& 주의집중 & 5 & .870 & \\
& 정서적 지지 & 7 & .846 & \\
& 정보적 지지 & 6 & .884 & .907 \\
사회적 지지 & 물질적 지지 & 6 & .913 & \\
& 평가적 지지 & 6 & .880 & \multicolumn{2}{c}{.909} \\
& 이직 의도 & 4 &
\end{tabular}

\section{3. 연구결과}

\section{1 일반적 특성}

본 연구대상자의 일반적 특성을 살펴보면, 유아 교사의 성별은 여자 115 명 $(100.0 \%)$ 으로 모두 여성 인 것으로 나타났으며, 연령은 40대 이상=50대 미만이 69명(60.0\%)으로 가장 많았고, 30대가 35명 $(30.4 \%), 20$ 대가 11 명 $(9.6 \%)$ 순으로 나타났다. 거주지 별로 살펴보면, 도시가 105 명 $(91.3 \%)$ 으로 농어 촌 10 명 $(8.7 \%)$ 보다 많은 것으로 조사되었다. 유아 교사의 일반적 특성에 대하여 분석결과는 [표 2] 와 같이 나타났다.

[표 2] 일반적 특성

[Table 2] General Characteristic

\begin{tabular}{|c|c|c|c|}
\hline \multirow{2}{*}{\multicolumn{2}{|c|}{ 구분 }} & \multicolumn{2}{|c|}{ 전체 $(\mathrm{N}=115)$} \\
\hline & & \multirow{2}{*}{$\begin{array}{l}\text { 빈도 } \\
0\end{array}$} & \multirow{2}{*}{$\begin{array}{c}\frac{\text { 비율 }(\%)}{0.0} \\
\end{array}$} \\
\hline \multirow{2}{*}{ 성별 } & 남자 & & \\
\hline & 여자 & 115 & 100.0 \\
\hline \multirow{3}{*}{ 연령 } & 20대 & 11 & 9.6 \\
\hline & 30대 & 35 & 30.4 \\
\hline & 40대 이상-50대 미만 & 69 & 60.0 \\
\hline \multirow{2}{*}{ 거주지 } & 도시 & 105 & 91.3 \\
\hline & 농어촌 & 10 & 8.7 \\
\hline
\end{tabular}




\section{2 주요 변수에 대한 기술통계}

\subsection{1 마음 챙김에 대한 기술통계}

유아 교사의 마음 챙김에 대한 척도는 5점 척도로 분석하였다. 분석결과를 보면, 마음 챙김 요인의 전체는 $\mathrm{M}=3.97$ 로 평균 점수보다 높게 나타났다. 구체적인 하위요인별로 살펴보면, 현재자각 $(\mathrm{M}=4.21)$ 요인이 가장 높게 나타났고, 비판단적 수용 $(\mathrm{M}=4.06)$, 주의집중 $(\mathrm{M}=3.94)$, 탈중심적 주의 $(\mathrm{M}=3.69)$ 순으로 나타났다. 유아 교사의 마음 챙김에 대한 기술통계를 분석결과는 [표 3]과 같이 나타났다.

[표 3] 마음 챙김에 대한 기술통계

[Table 3] Descriptive Statistics on Mindfulness

\begin{tabular}{|c|c|c|c|c|c|c|}
\hline & 구분 & $\mathrm{N}$ & 최소값 & 최대값 & $\mathrm{M}$ & SD \\
\hline \multirow{5}{*}{ 마음 챙김 } & 탈중심적 주의 & 115 & 2.20 & 5.00 & 3.69 & .87 \\
\hline & 비판단적 수용 & 115 & 2.20 & 5.00 & 4.06 & .89 \\
\hline & 현재자각 & 115 & 2.80 & 5.00 & 4.21 & .71 \\
\hline & 주의집중 & 115 & 2.00 & 5.00 & 3.94 & .78 \\
\hline & 전체 & 115 & 2.60 & 4.95 & 3.97 & .70 \\
\hline
\end{tabular}

\subsection{2 사회적 지지에 대한 기술통계}

유아 교사의 사회적 지지에 대한 측정 변수는 5 점 척도로 측정하였으며, 사회적 지지 요인의 전체 는 $\mathrm{M}=3.92$ 로 평균 점수보다 높게 나타났으며, 하위요인별로 살펴보면, 평가적 지지 $(\mathrm{M}=4.12)$ 요인 이 가장 높게 나타났고, 정서적 지지 $(\mathrm{M}=4.05)$, 정보적 지지 $(\mathrm{M}=3.95)$, 물질적 지지 $(\mathrm{M}=3.57)$ 순으로 나타났다. 유아 교사의 사회적 지지에 대한 기술통계를 분석결과는 [표 4]과 같이 나타났다.

[표 4] 사회적 지지에 대한 기술통계

[Table 4] Descriptive Statistics on Social Support

\begin{tabular}{|c|c|c|c|c|c|c|}
\hline & 구분 & $\mathrm{N}$ & 최소값 & 최대값 & $\mathrm{M}$ & $\mathrm{SD}$ \\
\hline \multirow{5}{*}{ 사회적 지지 } & 정서적 지지 & 115 & 2.71 & 5.00 & 4.05 & .66 \\
\hline & 정보적 지지 & 115 & 2.33 & 5.00 & 3.95 & .71 \\
\hline & 물질적 지지 & 115 & 1.50 & 4.67 & 3.57 & .86 \\
\hline & 평가적 지지 & 115 & 2.67 & 5.00 & 4.12 & .66 \\
\hline & 전체 & 115 & 2.30 & 4.83 & 3.92 & .64 \\
\hline
\end{tabular}




\subsection{3 이직 의도에 대한 기술통계}

http://dx.doi.org/10.47116/apjcri.2020.11.09

유아 교사의 이직 의도에 대한 측정 변수는 5점 척도로 측정하였으며, 이직 의도 요인은 $\mathrm{M}=2.23$ 으 로 평균보다 약간 낮은 수준으로 나타난 것을 알 수 있다. 유아 교사의 이직 의도에 대한 기술통 계를 분석결과는 [표 5]과 같이 나타났다.

[표 5] 이직 의도에 대한 기술통계

[Table 5] Descriptive Statistics on Turnover Intension

\begin{tabular}{cccccc}
\hline 구분 & $\mathrm{N}$ & 최소값 & 최대값 & $\mathrm{M}$ & $\mathrm{SD}$ \\
\hline 이직 의도 & 115 & 1.00 & 4.50 & 2.23 & 1.09 \\
\hline
\end{tabular}

\section{3 주요 변수 간의 상관관계}

유아 교사의 마음 챙김, 사회적 지지, 이직 의도와의 관련성을 살펴본 결과, 유아 교사가 인식하는 마음 챙김과 사회적 지지는 양의 상관관계가 나타났다(r=.544, $\mathrm{p}<.01)$. 반면, 마음 챙김과 이직 의도 는 약간의 음의 상관관계가 보여지는 것으로 확인되었다 $(\mathrm{r}=-.379, \mathrm{p}<.01)$. 한편 사회적 지지와 이직 의도는 약간의 음의 상관관계가 나타났다(r=-.438, $\mathrm{p}<.01)$. 이러한 결과는 각 변수들 간의 상관관계 성이 있다고 할 수 있다. 구체적인 각 변수 간의 상관분석결과는 [표 6]과 같이 나타났다.

[표 6] 주요 변수 간의 상관관계

[Table 6] Correlation between Key Variables

\begin{tabular}{cccc}
\hline 구분 & 마음 챙김 & 사회적 지지 & 이직 의도 \\
\hline 마음 챙김 & 1 & & \\
사회적 지지 & $.544^{* *}$ & 1 & 1 \\
이직 의도 & $-.379^{* *}$ & $-.438^{* *}$ & 1 \\
\hline
\end{tabular}

${ }^{*} \mathrm{p}<.05,{ }^{* *} \mathrm{p}<.01$

3.4 유아 교사의 마음 챙김, 사회적 지지, 이직 의도와의 관계

\subsection{1 유아 교사의 마음 챙김이 이직 의도에 미치는 영향}

유아 교사의 마음 챙김이 이직 의도에 미치는 영향을 분석하기 위하여 다중회귀분석을 수행하였 
다. 분석결과, 이직 의도에 대한 마음 챙김의 설명력을 의미하는 R2값이 .388로 나타나 전체 변동 의 $38.8 \%$ 로 회귀모형을 설명하고 있다. 또한 분산분석의 모형에 대한 분석 결과, 추정된 회귀 측정 모형은( $\mathrm{F}=17.444, \mathrm{p}<.000)$ 은 유의미한 것으로 보였다. 마음 챙김의 하위요인별로 영향력을 살펴보 면, 탈중심적 주의 $(\beta=-.960, \mathrm{p}<.001)$, 현재자각 $(\beta=-.746, \mathrm{p}<.001)$ 은 이직 의도에 부정적(-)으로 영향을 미치는 통계적으로 보였다. 반면 마음 챙김의 하위요인 비판단적 수용( $\beta=.899, \mathrm{p}<.001)$, 주의집중 $(\beta$ $=.396, \mathrm{p}<.01)$ 요인은 이직 의도에 부적(-)으로 유의한 영향을 미치지 않는 것으로 나타났다. 이는 유아 교사의 마음 챙김 하위요인인 탈중심적 주의, 현재자각 요인이 높을수록 이직 의도가 낮아진 다는 것을 의미하는 것이다. 유아 교사의 마음 챙김이 이직 의도에 미치는 영향을 살펴본 결과는 [표 7]과 같다.

[표 7] 유아 교사의 마음 챙김이 이직 의도에 미치는 영향

[Table 7] The Effect of Mindfulness of the Early Childhood Teacher on the Turnover Intention

\begin{tabular}{|c|c|c|c|c|c|c|c|}
\hline \multirow{2}{*}{ 종속변수 } & \multirow{2}{*}{ 독립변수 } & \multicolumn{2}{|c|}{ 비표준화 계수 } & \multirow{2}{*}{$\begin{array}{c}\text { 표준화 계수 } \\
\beta\end{array}$} & \multirow{2}{*}{$\mathrm{t}$} & \multirow{2}{*}{$\mathrm{p}$} & \multirow{2}{*}{$\begin{array}{l}\text { 공차 } \\
\text { 한계 }\end{array}$} \\
\hline & & B & 표준오차 & & & & \\
\hline \multirow{5}{*}{ 이직 의도 } & 상수 & 4.831 & .513 & & 9.419 & $.000^{* * *}$ & \\
\hline & $\begin{array}{c}\text { 탈중심적 } \\
\text { 주의 }\end{array}$ & -1.200 & .208 & -.960 & -5.781 & $.000^{* * *}$ & .202 \\
\hline & $\begin{array}{c}\text { 비판단적 } \\
\text { 수용 }\end{array}$ & 1.107 & .200 & .899 & 5.532 & $.000^{* * *}$ & .210 \\
\hline & 현재자각 & -1.152 & .190 & -.746 & -6.047 & $.000^{* * *}$ & .365 \\
\hline & 주의집중 & .555 & .174 & .396 & 3.183 & $.002^{* *}$ & .360 \\
\hline
\end{tabular}

$\mathrm{R}^{2}=.388$, 수정된 $\mathrm{R}^{2}=.366$

$\mathrm{F}=17.444, \mathrm{P}=.000$, Durbin-Watson=1.967

${ }^{*} \mathrm{p}<.05,{ }^{* *} \mathrm{p}<.01,{ }^{* * *} \mathrm{p}<.001$

\section{4 .2 유아 교사의 사회적 지지가 이직 의도에 미치는 영향}

유아 교사의 사회적 지지가 이직 의도에 미치는 영향을 알아보기 위하여 다중회귀분석을 실시하였 다. 분석 결과, 이직 의도에 대한 참여 동기의 설명력을 의미하는 R2값이 .479로 나타나 전체 변동 의 $47.9 \%$ 로 회귀모형을 설명하고 있다. 또한 분산분석의 모형에 대한 본석결과, 추정된 회귀모형 $(\mathrm{F}=25.282, \mathrm{p}<.000)$ 은 유의미한 것으로 조사되었다. 사회적 지지의 하위요인별로 영향력을 살펴보 면, 정보적 지지 $(\beta=-.447, \mathrm{p}<.01)$, 물질적 지지 $(\beta=-.996, \mathrm{p}<.001)$ 요인은 이직 의도에 부정적(-)으로 유영향이 미치는 것으로 보였다. 반면 사회적 지지의 하위요인 정서적 지지 $(\beta=.775, \mathrm{p}<.001)$, 평가 적 지지 $(\beta=.100, \mathrm{p}>.05)$ 요인은 이직 의도에 영향이 없는 것으로 확인되었다. 이는 유아 교사의 사 회적 지지 하위요인인 정보적 지지, 물질적 지지 요인이 높을수록 이직 의도가 낮아진다는 것을 
의미하는 것이다. 유아 교사의 사회적 지지가 이직 의도에 미치는 영향을 살펴본 결과는 [표 8]과 같다.

[표 8] 유아 교사의 사회적 지지가 이직 의도에 미치는 영향

[Table 8] The Effect of Social Support of Early Childhood Teachers on the Turnover Intention

\begin{tabular}{|c|c|c|c|c|c|c|c|}
\hline \multirow{2}{*}{ 종속변수 } & \multirow{2}{*}{ 독립변수 } & \multicolumn{2}{|c|}{ 비표준화 계수 } & 표준화 계수 & \multirow{2}{*}{$\mathrm{t}$} & \multirow{2}{*}{$\mathrm{p}$} & \multirow{2}{*}{$\begin{array}{l}\text { 공차 } \\
\text { 한계 }\end{array}$} \\
\hline & & B & 표준오차 & $\beta$ & & & \\
\hline \multirow{5}{*}{ 이직 의도 } & 상수 & 3.631 & .512 & & 7.087 & $.000^{* * *}$ & \\
\hline & 정서적 지지 & 1.276 & .284 & .775 & 4.487 & $.000^{* * *}$ & .159 \\
\hline & 정보적 지지 & -.692 & .220 & -.447 & -3.140 & $.002^{* *}$ & .233 \\
\hline & 물질적 지지 & -1.265 & .143 & -.996 & -8.814 & $.000^{* * *}$ & .371 \\
\hline & 평가적 지지 & .166 & .188 & .100 & .880 & .381 & .364 \\
\hline \multicolumn{8}{|c|}{$\mathrm{R}^{2}=.479$, 수정된 $\mathrm{R}^{2}=.460$} \\
\hline \multicolumn{8}{|c|}{$\mathrm{F}=25.282, \mathrm{P}=.000$, Durbin-Watson $=2.397$} \\
\hline
\end{tabular}

${ }^{*} \mathrm{p}<.05,{ }^{* *} \mathrm{p}<.01,{ }^{* * *} \mathrm{p}<.001$

\section{4. 결론 및 제언}

본 연구에서는 유아 교사의 마음 챙김, 사회적 지지, 이직 의도와의 관계에 대하여 분석하였다. 연 구결과를 토대로 구체적으로 논의하면 다음과 같다.

1) 유아 교사의 마음 챙김이 이직 의도에 미치는 영향을 살펴본 결과 마음 챙김의 하위요인인 탈중심적 주의, 현재자각은 이직 의도에 부적(-)으로 유의한 영향력을 미치는 것으로 나타났다. 반 면 마음 챙김의 하위요인 비판단적 수용, 주의집중 요인은 이직 의도에 부적(-)으로 유의한 영향을 미치지 않는 것으로 확인되었다. 이는 유아 교사의 마음 챙김 하위요인인 탈중심적 주의, 현재자각 요인이 높을수록 이직 의도가 낮아진다는 것을 의미하는 것이다.

2) 유아 교사의 마음 챙김과 사회적 지지가 이직 의도에 미치는 영향을 살펴본 결과 부적(-)으로 유의한 영향을 미치는 것으로 나타났다. 유아 교사의 마음 챙김, 사회적 지지, 이직 의도와의 관계 는 높은 수준의 양의 상관관계가 있음을 의미하는 것이다.

3) 유아 교사의 사회적 지지가 이직 의도에 미치는 영향을 살펴본 결과 사회적 지지의 하위요인 인 정보적 지지, 물질적 지지 요인은 이직 의도에 부적(-)으로 유의한 영향력을 미치는 것으로 나 타났다. 반면 사회적 지지의 하위요인 정서적 지지, 평가적 지지 요인은 이직 의도에 부적(-)으로 유의한 영향을 미치지 않는 것으로 나타났다. 이는 유아 교사의 사회적 지지 하위요인인 정보적 
지지, 물질적 지지 요인이 높을수록 이직 의도가 낮아진다는 것을 의미하는 것이다.

이상의 논의된 바와 같이 유아 교사 이직 의도의 완화 측면에서 유아 교사의 마음 챙김이 매우 중요하다. 따라서 본 연구의 시사점은 지금까지 유아 교사 이직 의도와 관련한 연구에서는 주로 심리적 소진이나 스트레스에 미치는 영향에 관한 연구 등이 있었으나, 본 연구에서는 유아 교사의 마음 챙김과 사회적 지지가 이직 의도에 미치는 영향을 분석하였다는 데 의의가 있다고 본다. 이 러한 연구결과를 토대로 유아 교사에게 있어서 지속성을 증가시킬 수 있는 프로그램 등의 개발이 필요하다. 향후 유아 교사를 대상으로 지속성 향상에 대해 심층적인 연구가 요구된다.

\section{References}

[1] Kim Yeon-ok, Chun Seong-moon, Lee Jung Hee, The development and validation of early childhood teachers burnout scale, The Journal of Korea Open Association for Early Childhood Education, (2012), Vol.17, No.4, pp.273-298, UCI: G704-000666.2012.17.4.001

[2] Han Ji-hyun, The Moderating Effect of Teaching Efficacy on the Relationship between Job Stress and Teacher-Child Interaction in Early Childhood Teachers - For Preschool Teachers of 5 Years Old -, The Korea Association of Child Care and Education, (2020), No.121, pp.21-39, DOI: 10.37918/kce.2020.03.121.21

[3] Jeong Kyung-Jin, Yoon Hye-Mi, Child-Care Teachers' Emotional Labor, Job Stress, Psychological Well-being, and Turnover Intention, KThe Korea Association of Child Care and Education, (2016), No.96, pp.129-152, UCI: G704-000724.2016..96.006

[4] Kyung Min Lee, Ju Yeon Park, A study of relationships among Happiness and Job Related Variables of Kindergarten Teachers for young children, Korean Journal of Early Childhood Education, (2015), Vol.35, No.6, pp.33-48, DOI: 10.18023/kjece.2015.35.6.002

[5] Kwon Young-ran, Moon Young-kyung, An analysis on meditating effect between the teacher efficacy and the job stress with regard to child care teacher's social support and turnover, Korean Journal of Child Education and Care, (2016), Vol.16, No.1, pp.99-119, UCI: G704-SER0000088663.2016.16.1.001

[6] Lim Nan-joo, Kim Anna, Effects of Early Childhood Teacher job stress on the turnover intention and job satisfaction, Journal of Korea Academia-Industrial cooperation Society, (2014), Vol.15, No.8, pp.4972-4980, DOI: $10.5762 /$ KAIS.2014.15.8.4972

[7] Choe Hyung Sung, The Effects of Resilience, Job Satisfaction, and Burnout on Intention To Leave of Infant Teachers in Korea, Journal of Early Childhood Education \& Educare Welfare, (2017), Vol.21, No.3, pp.129-149, DOI: 10.22590/ecee.2017.21.3.129

[8] Jang Eunhee, Lee Byungho, The mediating effects of mindfulness and acceptance in the relationship between parent-related emotional labor and burnout in early childhood teachers, The Journal of Korea Open Association for Early Childhood Education, (2020), Vol.25, No.1, pp.287-322, DOI: 10.20437/KOAECE25-1-12

[9] Jeong Hye-young, Lee Kyung-hwa, The Path Model of Early Childhood Teachers' Turnover Intentions with 
Social Support, Depression, and Burnout, Early Childhood Education Research \& Review, (2014), Vol.18, No.3, pp.159-181, UCI: G704-000814.2014.18.3.016

[10] Jeong Soonhee, Choi Youngmi, Lee Heeyoung, The Influence of Teacher Efficacy and Emotional Support on the Burnout of Infant Nursing Teachers, Journal of Future Early Childhood Education, (2013), Vol.20, No.4, pp.193-215, UCI: G704-000819.2013.20.4.004

[11] W. K. Lee, An examination of the structural relationships among stress of middle-aged women, mindfulness, self-compassion, and emotional well-being, and effectiveness of a mindfulness enhancement program, Department of Psychology The Graduate School of Ewha Womans University, Doctoral Thesis, (2008)

[12] G. S. Kim, The Effects of Social Support of Parents of Children with Disabilities on Family Health : Moderating Effect of Self-Esteem, Department of Education Dongbang Culture University, Doctoral Thesis, (2017)

[13] H. J. Park, The Influence of Conflict in Social Welfare Organization on Organizational Commitment and Turnover Intention-Focused on the Mediating Effect of Job Satisfaction and the Moderating Effect of Social Support, Department of Social Welfare Graduate School, Cheongju University, Doctoral Thesis, (2011) 